Article

\title{
In Vivo Toxicity Evaluation of Sugar Adulterated Heterotrigona itama Honey Using Zebrafish Model
}

\author{
Rafieh Fakhlaei ${ }^{1}$, Jinap Selamat ${ }^{1,2, *(\mathbb{D}}$, Ahmad Faizal Abdull Razis ${ }^{2,3} \mathbb{D}^{\circ}$, Rashidah Sukor ${ }^{1,2}{ }^{\oplus}$, Syahida Ahmad ${ }^{4}$, \\ Arman Amani Babadi ${ }^{5}$ and Alfi Khatib ${ }^{6}$
}

1 Food Safety and Food Integrity (FOSFI), Institute of Tropical Agriculture and Food Security, Universiti Putra Malaysia, Serdang 43400, Selangor, Malaysia; rafieh.fakhlaei@gmail.com (R.F.); rashidah@upm.edu.my (R.S.)

2 Department of Food Science, Faculty of Food Science and Technology, Universiti Putra Malaysia, Serdang 43400, Selangor, Malaysia; madfaizal@upm.edu.my

3 Natural Medicines and Products Research Laboratory, Institute of Bioscience, Universiti Putra Malaysia, Serdang 43400, Selangor, Malaysia

4 Department of Biochemistry, Faculty of Biotechnology \& Biomolecular Sciences, Universiti Putra Malaysia, Serdang 43400, Selangor, Malaysia; syahida@upm.edu.my

5 Department of Molecular Medicine, School of Advanced Technologies in Medicine, Tehran University of Medical Sciences, Tehran 55469-14177, Iran; ar.amani65@gmail.com

6 Department of Pharmaceutical Chemistry, Kulliyyah of Pharmacy, International Islamic University Malaysia, Kuantan 25200, Pahang, Malaysia; alfikhatib@iium.edu.my

* Correspondence: jinap@upm.edu.my; Tel.: +60-38-9769-1099

Citation: Fakhlaei, R.; Selamat, J.; Razis, A.F.A.; Sukor, R.; Ahmad, S.; Amani Babadi, A.; Khatib, A. In Vivo Toxicity Evaluation of Sugar Adulterated Heterotrigona itama Honey Using Zebrafish Model. Molecules 2021, 26, 6222. https:// doi.org/10.3390/molecules26206222

Academic Editor: Juraj Majtan

Received: 5 July 2021

Accepted: 6 August 2021

Published: 15 October 2021

Publisher's Note: MDPI stays neutral with regard to jurisdictional claims in published maps and institutional affiliations.

Copyright: (c) 2021 by the authors. Licensee MDPI, Basel, Switzerland. This article is an open access article distributed under the terms and conditions of the Creative Commons Attribution (CC BY) license (https:/ / creativecommons.org/licenses/by/ $4.0 /)$.
Abstract: Honey is prone to be adulterated through mixing with sugars, cheap and low-quality honey, and other adulterants. Consumption of adulterated honey may cause several health issues such as weight gain, diabetes, and liver and kidney dysfunction. Therefore, studying the impact of consumption of adulterated honey on consumers is critical since there is a lack of study in this field. Hence, the aims of this paper were: (1) to determine the lethal concentration $\left(\mathrm{LC}_{50}\right)$ of adulterated honey using zebrafish embryo, (2) to elucidate toxicology of selected adulterated honey based on lethal dose $\left(\mathrm{LD}_{50}\right)$ using adult zebrafish, (3) to determine the effects of adulterated honey on histological changes of zebrafish, and (4) to screen the metabolites profile of adulterated honey by using zebrafish blood serum. The $\mathrm{LC}_{50}$ of Heterotrigona itama honey (acacia honey) and its sugar adulterants (light corn sugar, cane sugar, inverted sugar, and palm sugar in the proportion of 1-3\% $(w / w)$ from the total volume) was determined by the toxicological assessment of honey samples on zebrafish embryos (different exposure concentrations in 24, 48, 72, and $96 \mathrm{~h}$ postfertilization (hpf)). Pure H. itama honey represents the $\mathrm{LC}_{50}$ of $34.40 \pm 1.84(\mathrm{mg} / \mathrm{mL})$ at $96 \mathrm{hpf}$, while the inverted sugar represents the lowest $\mathrm{LC}_{50}(5.03 \pm 0.92 \mathrm{mg} / \mathrm{mL})$ among sugar adulterants. The highest concentration $(3 \%)$ of sugar adulterants were used to study the toxicology of adulterated honey using adult zebrafish in terms of acute, prolong-acute, and sub-acute tests. The results of the $\mathrm{LD}_{50}$ from the sub-acute toxicity test of pure H. itama honey was $2.33 \pm 0.24(\mathrm{mg} / \mathrm{mL})$. The histological studies of internal organs showed a lesion in the liver, kidney, and spleen of adulterated treated-honey groups compared to the control group. Furthermore, the LC-MS/MS results revealed three endogenous metabolites in both the pure and adulterated honey treated groups, as follows: (1) S-Cysteinosuccinic acid, (2) 2,3-Diphosphoglyceric acid, and (3) Cysteinyl-Tyrosine. The results of this study demonstrated that adulterated honey caused mortality, which contributes to higher toxicity, and also suggested that the zebrafish toxicity test could be a standard method for assessing the potential toxicity of other hazardous food additives. The information gained from this research will permit an evaluation of the potential risk associated with the consumption of adulterated compared to pure honey.

Keywords: Heterotigona itama honey; honey quality; adulteration; Danio rerio; toxicity assessment 


\section{Introduction}

The standards of Codex Alimentarius [1] define honey as the natural sweet substance produced by honey bees from the nectar of plants or secretions of living parts of plants. The honeybees can collect and transform it by mixing it with specific substances of their own, then deposit it, dehydrate it, and store it in the honeycomb to ripen and mature. The harvested honey from honeybees can be consumed not only as a sweetener but also as a medicine due to its therapeutic effect on human health.

Honey contains mainly sugar and more than 200 other compounds [2]. Sugars, as a major component of carbohydrates, comprise 95-99\% of honey's dry matter [3]. Fructose and glucose are the main sugars in H. itama honey in the proportion of $13.00 \pm 0.21(\mathrm{~g} / 100 \mathrm{~g}$ honey) for the former and $11.69 \pm 0.56$ (g/100 g honey) for the latter [4]. In addition to fructose and glucose, several other disaccharides and oligosaccharides, including sucrose $0.31 \pm 0.01$ (g/100 g honey), maltose $22.56 \pm 1.22$ (g/100 g honey), maltotriose, and panose, can be found. Organic acids, minerals, and trace elements such as calcium, potassium, sodium, magnesium, phosphorus, sulphur, iron, zinc, copper, and manganese are other components presented in pure H. itama [3].

In general, honey is perceived as a high-quality product and the most susceptible to be adulterated or have incorrect labelling and fraudulent mixing with lower-cost and lowquality honey, sugars, and other substances. Consequently, owing to therapeutic properties, limited availability, and high prices, honey is subjected to adulteration. Adulterants are referring to any substances that are added to the original and pure product to corrupt, debase, or prepare for sale by replacing more valuable substances with less valuable ones. Honey can be adulterated directly (bee-feeding) or indirectly (addition of adulterants). Cheap sweeteners such as cane sugar, corn syrup, maltose, and high fructose syrup are being used commonly to adulterate honey [5]. Honey adulteration has a major impact on economic loss not only due to declining honey quality but also by making difficulties in the marketing of pure honey [6]. Honey has been targeted for adulteration worldwide due to the high demand [7]. Therefore, international committees have focused on the quality control of honey and safety protocols.

Inexpensive sugars or industrial syrups are generally used for the adulteration of honey. Soares, et al. [8] described well-known adulterants produced from sugar cane or sugar beet, such as sugar syrups, corn syrup (CS) and high-fructose corn syrup (HFCS), glucose syrup (GS), sucrose syrup, inverted syrup (IS), or high-fructose inulin syrup (HFIS). These sugars may replicate the natural taste of the honey while increasing the yield volume, but the lack of nutrition and therapeutic substances are unavoidable. Moreover, the addition of these sugars may put the consumers' health in danger and cause perceptible side effects.

The study of the impact of adulterated honey on humans is noticeably important. However, human individuals cannot be used as a test model due to significant costs and harm toward human beings, and it is not ethically justified. Moreover, the common animal models, such as mice, rabbits, primates, and chickens, require plenty of time, money, and training of the operators. Therefore, in this study, the zebrafish (Danio rerio) has been selected as an animal test model due to high transparency, early life stage development, and cost reduction. $70 \%$ of genes which are associated with diseases in human body have functional homology in zebrafish [9]. While the early life stage of zebrafish (embryonic stage) can provide primary information, acute and chronic tests on adult zebrafish allow the observation of any sign regarding toxicity.

Based on previous research, carbohydrates are used in fish diets primarily as energy sources and for their binding properties. Starches, pectin, and hemicelluloses have pellet-binding characteristics of great importance to feed manufacturers. Therefore, carbohydrates may be added to the feed-in excess of the amounts that can be efficiently utilized for energy by the fish. As zebrafish are warm water omnivores, carbohydrates are likely an important component of their diet. Indeed, recent work on adult zebrafish has demonstrated that the amount of carbohydrate in the diet is positively correlated with growth rate. 
Eames, et al. [10] showed that zebrafish, similar to other omnivores, metabolize glucose faster than carnivorous teleosts. The relatively fast glucose metabolism of zebrafish should facilitate laboratory studies of pancreas and liver function. This literature proves that "carbohydrates" are the typical food component in the fish's diet.

Thanks to the development of analytical methods, many studies have been conducted to detect food authentication and fraud. Here is a brief example of these studies; high-performance anion-exchange chromatography with pulsed amperometric detection (HPAEC-PAD) for the detection of CS, and stable carbon isotope ratio analysis (SCIRA) for the detection of high fructose syrup (HFS) [11], GC-MS for the detection of CS [12], cavity ring-down spectroscopy (CRDS) and isotope ratio mass spectrometry (IRMS) for the detection of CS [13], Raman spectroscopy for the detection of CS [14], matrix-assisted laser desorption/ionization mass spectrometry (MALDI-MS) for the detection of IS and CS [15], and headspace-gas chromatography coupled to ion mobility spectrometry (HS-GC-IMS) for the detection of CS [16]. On the other hand, ultrahigh-performance liquid chromatography coupled with quadrupole time-of-flight mass spectrometry (UHPLC/Q-TOF-MS) was applied for indirect adulteration of honey through bee feeding with multi-class sugar syrups, such as CS and IS [17]. Hence, the liquid chromatography-electrochemical detection (LC-ECD) [18] and laser-induced breakdown spectroscopy (LIBS) [19] methods were used for the detection of acacia honey blended with rape honey.

In this study, the $\mathrm{LC}_{50}$ and $\mathrm{LD}_{50}$ of Heterotrigona itama honey (acacia honey) and its sugar adulterants have been assessed and discussed, while histology provided depth observation through organs. In addition, the LCMS/MS-based metabolite shifting in the serum of adult zebrafish after treatment with pure and adulterated H. itama have been identified.

\section{Results}

\subsection{Brix Value (\%) Analysis}

The Brix value (\%) characterization of pure honey and sugar adulterated H. itama honey are presented in Table 1. The Brix value of pure H. itama honey was $65.40 \pm 0.10$, which was not significantly different $(p>0.05)$ from sugar adulterated H.itama honey with different concentrations $(1,2$, and $3 \%)$.

Table 1. The Brix value (\%) of $H$. itama honey adulterated with different sugars at different concentrations.

\begin{tabular}{|c|c|c|}
\hline Samples & $(\%)$ & Brix $(\%)$ \\
\hline Pure H. itama honey & 0 & $65.40 \pm 0.10^{a b c}$ \\
\hline \multirow{3}{*}{ Palm sugar } & 1 & $64.92 \pm 2.10^{a b c}$ \\
\hline & 2 & $64.62 \pm 1.49^{b c}$ \\
\hline & 3 & $66.04 \pm 0.19^{a b}$ \\
\hline \multirow{3}{*}{ Cane sugar } & 1 & $64.72 \pm 1.12^{b c}$ \\
\hline & 2 & $65.41 \pm 1.16^{\mathrm{abc}}$ \\
\hline & 3 & $65.53 \pm 0.49 a b c$ \\
\hline \multirow{3}{*}{ Light corn syrup } & 1 & $66.14 \pm 0.34^{\mathrm{ab}}$ \\
\hline & 2 & $66.46 \pm 0.57^{\mathrm{a}}$ \\
\hline & 3 & $65.83 \pm 0.95^{\mathrm{ab}}$ \\
\hline \multirow{3}{*}{ Inverted sugar } & 1 & $64.08 \pm 0.72^{c}$ \\
\hline & 2 & $65.56 \pm 0.60^{a b c}$ \\
\hline & 3 & $65.69 \pm 0.44^{\mathrm{ab}}$ \\
\hline
\end{tabular}

Values within the same column with different letters $(\mathrm{a}-\mathrm{c})$ are significantly different $(p<0.05)$. 


\subsection{Lethal Concentration $\left(L C_{50}\right)$ of Pure and Adulterated Honey}

$\mathrm{LC}_{50}$ of pure and sugar-adulterated $H$. itama honey on zebrafish embryos at $96 \mathrm{hpf}$ is shown in Table 2. Pure H. itama honey was adulterated with four types of sugar (cane sugar, inverted sugar, palm sugar, and light corn syrup in the concentration of $1 \%, 2 \%$, and $3 \%$, respectively). The $\mathrm{LC}_{50}$ of pure $H$. itama honey was $34.40 \pm 1.84(\mathrm{mg} / \mathrm{mL})$, which was significantly $(p \leq 0.05)$ higher than sugar adulterated $H$. itama honey. Inverted sugar showed the lowest LC50 in all three concentrations among the whole sugar adulterants significantly $(p \leq 0.05)$, which indicated the highest toxic effect. The $\mathrm{LC}_{50}$ was decreased significantly $(p \leq 0.05)$ with increasing adulterant concentration. The inverted sugar at a concentration of $3 \%$ had the lowest $\mathrm{LC}_{50}(5.03 \pm 0.92)$, followed by light corn syrup (7.60 \pm 0.45$)$, palm sugar $(8.87 \pm 1.90)$, and finally, cane sugar $(9.87 \pm 0.09)(p \leq 0.05)$ (Table 2). Since there is no mortality observed in the control group (Embryo medium, E3), the result is not included in Table 2.

Table 2. The $\mathrm{LC}_{50}$ of pure and sugar adulterated H. itama honey at $96 \mathrm{hpf}$.

\begin{tabular}{|c|c|c|}
\hline Sugar Adulterant & $\%$ Sugar & $\mathrm{LC}_{50}(\mathrm{mg} / \mathrm{mL})$ \\
\hline Control & 0 & $34.40 \pm 1.84^{a}$ \\
\hline \multirow{3}{*}{ Cane Sugar } & 1 & $18.94 \pm 1.17^{b}$ \\
\hline & 2 & $12.51 \pm 1.73^{c}$ \\
\hline & 3 & $9.87 \pm 0.09^{d}$ \\
\hline \multirow{3}{*}{ Palm Sugar } & 1 & $14.25 \pm 1.17^{\mathrm{e}}$ \\
\hline & 2 & $11.98 \pm 0.66^{\mathrm{f}}$ \\
\hline & 3 & $8.87 \pm 1.90 \mathrm{~g}$ \\
\hline \multirow{3}{*}{ Light corn syrup } & 1 & $13.52 \pm 0.71^{h}$ \\
\hline & 2 & $10.12 \pm 1.18^{i}$ \\
\hline & 3 & $7.60 \pm 0.45^{j}$ \\
\hline \multirow{3}{*}{ Inverted sugar } & 1 & $10.66 \pm 0.40^{\mathrm{k}}$ \\
\hline & 2 & $8.29 \pm 1.00^{1}$ \\
\hline & 3 & $5.03 \pm 0.92^{\mathrm{m}}$ \\
\hline
\end{tabular}

Note: Values within the same column with different letters $(\mathrm{a}-\mathrm{m})$ are significantly different $(p<0.05)$.

\subsection{Mortality Rate}

To evaluate the possible toxicity of adulterated honey on zebrafish embryos, the mortality rate as a developmental phenotype was analyzed. The mortality rate of zebrafish embryos after exposure to sugar adulterated H. itama honey at $96 \mathrm{hpf}$, is illustrated in Figure 1. Lethality was observed right after exposure in a dose-dependent manner between 4 and $40 \mathrm{mg} / \mathrm{mL}$ of pure and adulterated honey. The highest concentration $(40 \mathrm{mg} / \mathrm{mL})$ of sugar adulterated $\mathrm{H}$. itama honey indicated $100 \%$ lethality of embryos in all four sugar adulterants at a concentration of $3 \%$, which was significantly $(p \leq 0.05)$ different from pure H. itama honey.

\subsection{Hatchability of Zebrafish Embryos}

In general, hatching of the embryo into larvae happens from 48 to $72 \mathrm{hpf}$. The hatching rate $(\%)$ of pure and 3\% sugar adulterated for H. itama honey is displayed in Figure 2a. The presented data shows that the early hatching rate of embryos increased significantly $(p \leq 0.05)$ in a time-dependent manner. Our results showed that the hatching rate of the sugar adulterated honey treated group started before $48 \mathrm{hpf}$, which is detrimental for fish. 



Figure 1. Dose-dependent effect of pure and sugar adulterated H. itama on zebrafish embryo mortality rates at $96 \mathrm{hpf}$ (a) cane sugar, (b) palm sugar, (c) inverted sugar, and (d) light corn syrup.
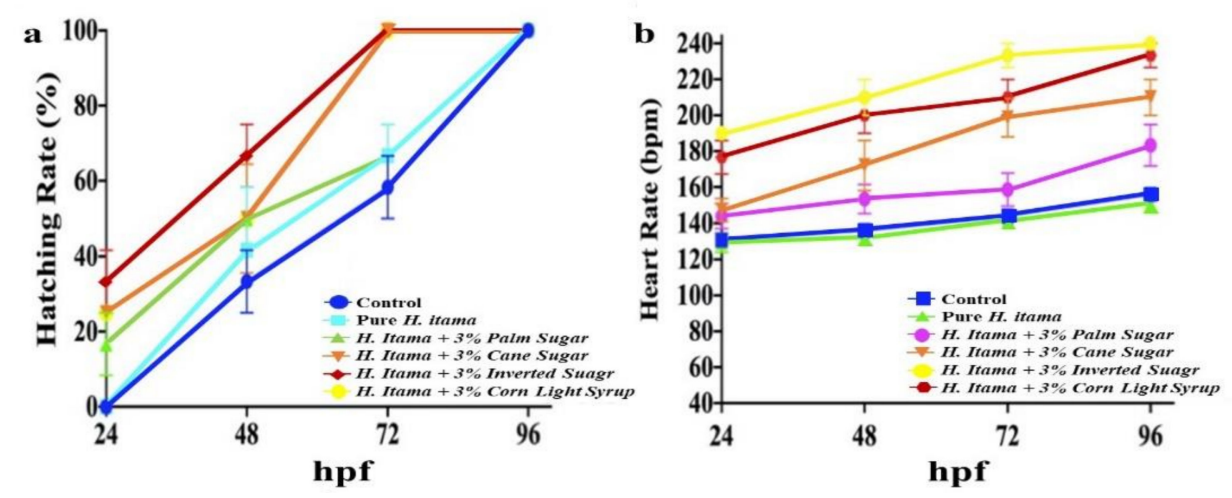

Figure 2. Concentration and time-dependent effect of pure H. itama honey on zebrafish embryos: (a) hatching rates and (b) heartbeat.

\subsection{Heartbeat Rate}

The heartbeat rate of zebrafish embryos and hatched larvae measured at 24, 48, 72, and $96 \mathrm{hpf}$ and statistical analyses are presented in Figure $2 \mathrm{~b}$. According to Figure $2 \mathrm{~b}$, there is a significant $(p \leq 0.05)$ increase in the number of heartbeats per minute (bpm) across embryonic development (24-96 hpf) treated with sugar adulterated H. itama honey in comparison to those treated with pure H. itama honey.

\subsection{Acute Toxicity Test}

The acute toxicity of pure $\mathrm{H}$. itama honey in adult zebrafish (during the period of $24 \mathrm{~h}$ ) in 3 different doses of low $(1 \mathrm{mg} / \mathrm{gbw})$, medium ( $5 \mathrm{mg} / \mathrm{gbw})$, and high $(10 \mathrm{mg} / \mathrm{gbw})$ is presented in Table 3. The result in Table 3 showed that the safe dose for pure honey was at the low dosage with a mortality rate (\%) of $10 \%$ for pure $\mathrm{H}$. itama honey; Meanwhile, in the high dosage, $100 \%$ mortality rate $(\%)$ was reached for pure H. itama honey. However, the $\mathrm{LD}_{50}$ value of $H$. itama was $4.70 \pm 1.77$ (mg/g bw). Among the control group, no mortality was observed during the acute toxicity test. Figure 3 indicates the percentage 
of the mortality rate of pure $H$. itama during the acute toxicity test $(24 \mathrm{~h})$. The $\mathrm{LD}_{50}$ value was obtained by converting the percentage of mortality to probits (probability unit) and taking the logarithm of the concentrations in order to plot the probits versus the logarithm of the concentrations graph. Finally, by fitting the regression line, the $\mathrm{LD}_{50}$ value has been revealed.

Table 3. Acute toxicity test of pure honey H. itama in adult zebrafish (Danio rerio).

\begin{tabular}{ccccc}
\hline Sample & Dose $(\mathbf{m g} / \mathbf{g} \cdot \mathbf{b w})$ & Total Fish Tested & Mortality (\%) & LD $_{\mathbf{5 0}}(\mathbf{m g} / \mathbf{g} \cdot \mathbf{b w})$ \\
\hline \multirow{2}{*}{ H. itama } & Low & 15 & 10 & \multirow{2}{*}{$4.70 \pm 1.77$} \\
\cline { 2 - 4 } & Medium & 15 & 60 & \\
\cline { 2 - 4 } Fish tank water & High & 15 & 100 & - \\
\hline
\end{tabular}

Note: Data are shown as the mean \pm SEM. Low: $1 \mathrm{mg} / \mathrm{g} \cdot \mathrm{bw}$, medium: $5 \mathrm{mg} / \mathrm{gbw}$, high: $10 \mathrm{mg} / \mathrm{gbw}$. LD: lethal dose; hpf: hour post-fertilization; SEM: standard error of the mean.

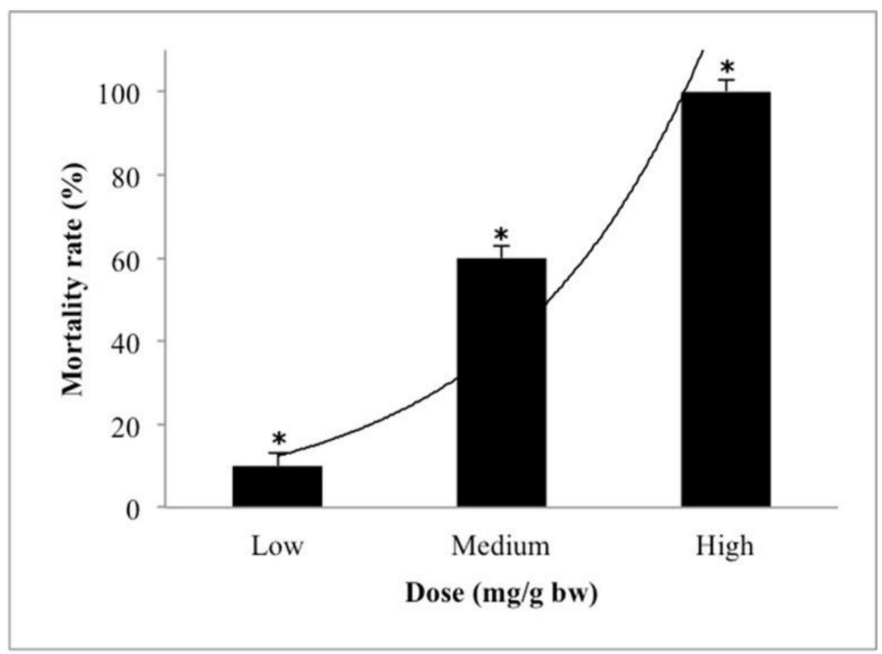

Figure 3. Dose-dependent effect of pure H. itama on mortality rate (\%) of adult zebrafish during $24 \mathrm{~h}$ acute toxicity test. Low: $1 \mathrm{mg} / \mathrm{g} \cdot \mathrm{bw}$, medium: $5 \mathrm{mg} / \mathrm{g} \cdot \mathrm{bw}$, high: $10 \mathrm{mg} / \mathrm{g} \cdot \mathrm{bw}$. Values significantly different are indicated by asterisks $\left({ }^{*} p \leq 0.05\right)$.

\subsection{Prolong-Acute Toxicity Test}

Table 4 presents the prolong-acute toxicity of pure H. itama honey in adult zebrafish for $72 \mathrm{~h}$ in three different dosages of low $(0.5 \mathrm{mg} / \mathrm{g} \cdot \mathrm{bw})$, medium $(1 \mathrm{mg} / \mathrm{g} \cdot \mathrm{bw})$, and high $(3 \mathrm{mg} / \mathrm{gbw})$. The $\mathrm{LD}_{50}$ of pure H. itama honey was $5.22 \pm 1.31(\mathrm{mg} / \mathrm{g} \cdot \mathrm{bw})$. Among the control group, no mortality was observed during the prolong-acute toxicity test. Figure 4 showed the mortality rate (\%) of pure H. itama honey during $72 \mathrm{~h}$ of the prolong-acute toxicity test. There was a concentration-dependent response, and increasing the dosage of honey led to a rise in the mortality rate. Therefore, 0.5 and $1(\mathrm{mg} / \mathrm{gbw})$ dosages were chosen as the safe dose for the sub-acute study because less than $50 \%$ of zebrafishes were killed in this dose.

Table 4. The prolong-acute toxicity test of pure H. itama honey in adult zebrafish (Danio rerio).

\begin{tabular}{ccccc}
\hline Sample & Dose $(\mathbf{m g} / \mathbf{g}$ bw) & Total Fish Tested & Mortality $\mathbf{( \% )}$ & LD $\left._{\mathbf{5 0}} \mathbf{( m g / g} \cdot \mathbf{b w}\right)$ \\
\hline \multirow{3}{*}{ H. itama } & Low & 15 & 10 & \\
\cline { 2 - 4 } & Medium & 15 & 30 & \\
\cline { 2 - 4 } & High & 15 & 100 & \\
\hline Fish tank water & - & 15 & 0 & -
\end{tabular}

Note: Data are shown as the mean \pm SEM. Low: $0.5 \mathrm{mg} / \mathrm{g} \cdot \mathrm{bw}$, medium: $1 \mathrm{mg} / \mathrm{g} \cdot \mathrm{bw}$, high: $3 \mathrm{mg} / \mathrm{g} \cdot \mathrm{bw}$. LD: lethal dose; hpf: hour post-fertilization; SEM: standard error of the mean. 


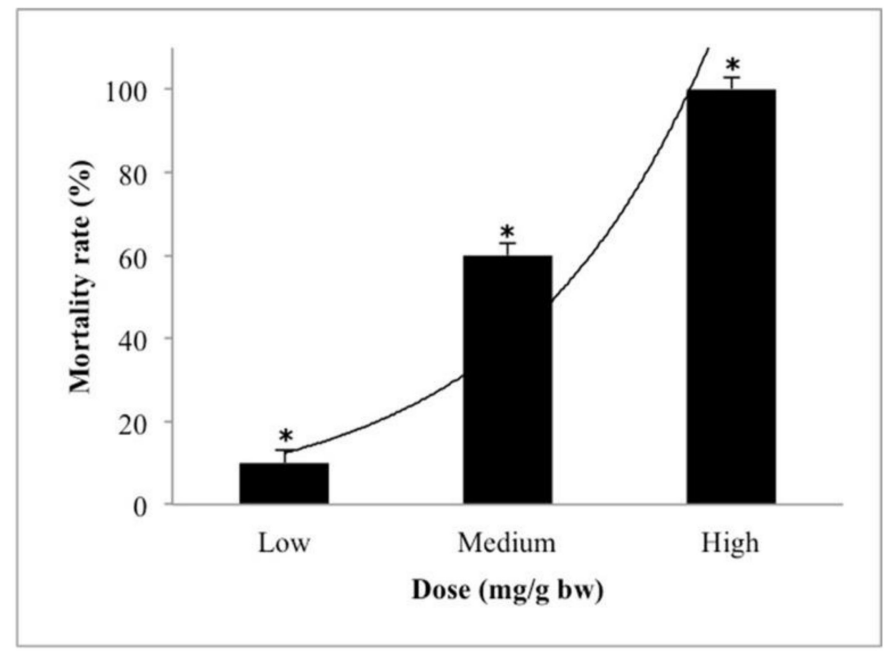

Figure 4. Dose-dependent effect of pure H. itama honey on mortality rate (\%) of adult zebrafish during $72 \mathrm{~h}$ of the prolong-acute toxicity test. Low: $0.5 \mathrm{mg} / \mathrm{g} \cdot \mathrm{bw}$, medium: $1 \mathrm{mg} / \mathrm{g} \cdot \mathrm{bw}$, high: $3 \mathrm{mg} / \mathrm{g} \cdot \mathrm{bw}$. Values significantly different are indicated by asterisks $\left({ }^{*} p \leq 0.05\right)$.

\subsection{Sub-Acute Toxicity Test}

Table 5 shows the median lethal dose $\left(\mathrm{LD}_{50}\right)$ of pure and sugar adulterated $H$. itama. According to Table 5, inverted sugar with $\mathrm{LD}_{50}$ of $0.20 \pm 0.06(\mathrm{mg} / \mathrm{mL})$ had the significantly ( $p \leq 0.05$ ) highest toxicity among all sugar adulterants, followed by light corn syrup $(0.35 \pm 0.07 \mathrm{mg} / \mathrm{mL})$, palm sugar $(0.80 \pm 0.16 \mathrm{mg} / \mathrm{mL})$, and cane sugar $(1.13 \pm 0.52 \mathrm{mg} / \mathrm{mL})$. With the aim to determine the no observed adverse effect level (NOAEL), there was no lethality observed at a low dose for pure H. Itama honey after 14 days of the sub-acute toxicity test.

Table 5. Sub-acute toxicity test of pure and sugar adulterated H. itama honey in adult zebrafish (Danio rerio) after 14 days.

\begin{tabular}{|c|c|c|c|c|}
\hline Sample & Dose (mg/g BW) & Total Fish Tested & Mortality (\%) & $\mathrm{LD}_{50}(\mathrm{mg} / \mathrm{mL})$ \\
\hline \multirow{3}{*}{ H.itama } & Low & 15 & 0 & \multirow{3}{*}{$2.33 \pm 0.24^{\mathrm{a}}$} \\
\hline & Medium & 15 & 20 & \\
\hline & High & 15 & 40 & \\
\hline \multirow{3}{*}{ H.itama $+3 \%$ Cane sugar } & Low & 15 & 20 & \multirow{3}{*}{$1.13 \pm 0.12^{b}$} \\
\hline & Medium & 15 & 40 & \\
\hline & High & 15 & 50 & \\
\hline \multirow{3}{*}{ H.itama $+3 \%$ Palm sugar } & Low & 15 & 30 & \multirow{3}{*}{$0.80 \pm 0.16^{c}$} \\
\hline & Medium & 15 & 30 & \\
\hline & High & 15 & 60 & \\
\hline \multirow{3}{*}{$\begin{array}{c}\text { H.itama }+3 \% \text { Light corn } \\
\text { syrup }\end{array}$} & Low & 15 & 30 & \multirow{3}{*}{$0.35 \pm 0.07^{\mathrm{d}}$} \\
\hline & Medium & 15 & 30 & \\
\hline & High & 15 & 80 & \\
\hline \multirow{3}{*}{$\begin{array}{c}\text { H.itama }+3 \% \text { Inverted } \\
\text { sugar }\end{array}$} & Low & 15 & 30 & \multirow{3}{*}{$0.20 \pm 0.06^{\mathrm{e}}$} \\
\hline & Medium & 15 & 60 & \\
\hline & High & 15 & 100 & \\
\hline Fish tank water & - & 15 & 0 & - \\
\hline
\end{tabular}

Note: Data are shown as the mean \pm SEM. Means with different small letters (a-e) in the same column are significantly different $(p \leq 0.05)$. Low: $0.1 \mathrm{mg} / \mathrm{g} \cdot \mathrm{bw}$, medium: $0.5 \mathrm{mg} / \mathrm{g} \cdot \mathrm{bw}, \mathrm{high}: 1 \mathrm{mg} / \mathrm{g} \cdot \mathrm{bw}$. LD: lethal dose; hpf: hour post-fertilization; SEM: standard error of the mean. 


\section{Histology}

Microscopic examination of the H\&E-stained liver, kidneys, and spleen tissue of non-treated and treated zebrafish is shown in Figure 5. The liver of control and pure honey treated zebrafishes showed the normal structure of the hepatic lobules, hepatocytes, and sinusoids. In contrast, adulterated honey treated zebrafish groups exhibited several histopathological changes, including foamy hepatocytes, focal necrosis, and infarction, as well as a significant increase in lesion score. The kidneys of the control group showed fairly normal vacuolated renal tubules, while the kidneys of zebrafish from the adulterated honey group showed significant degenerative changes. The spleen tissue of the control group showed a connective tissue framework (which includes capsule, trabeculae, and reticular connective tissue) and parenchyma of lymphoid tissue in the form of white (lymphoid nodules) and red pulp and no significant lesion. The pure honey showed no significant lesion in the spleen, while adulterated groups showed depleted lymphocytes leading to small follicles and relatively large red pulp.

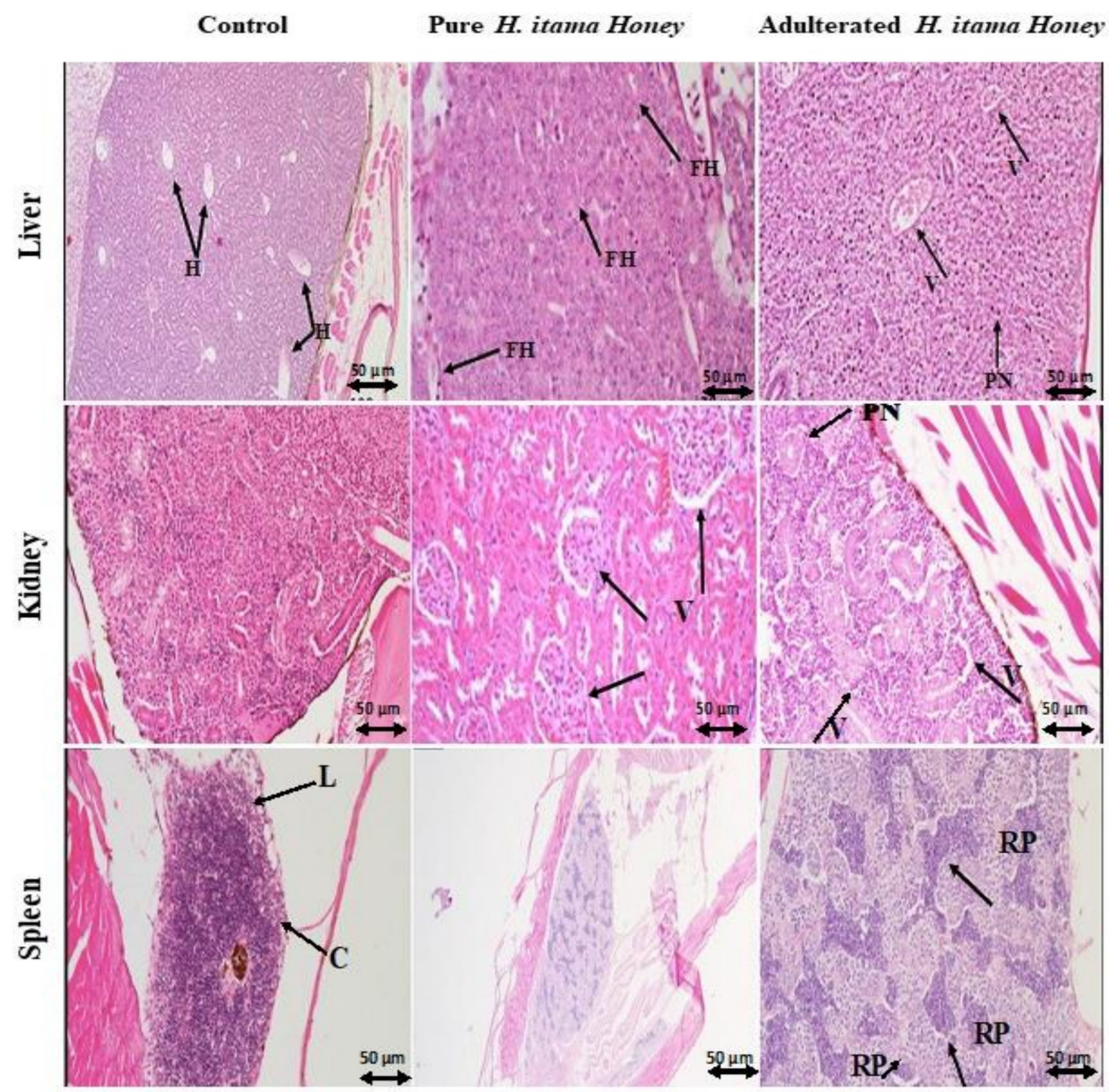

Figure 5. Histological alteration in the liver, kidney, and spleen of zebrafish treated with a different type of honey. Control groups with normal histological structure, the pure honey group with normal to the mild lesion, and the adulterated honey group with moderate to the severe lesion, $\mathrm{H}$ : hepatocyte, FH: foamy hepatocyte, V: vacuolation, PN: pyknotic nucleus, C: capsule, L: lymphoid tissue, RP: red pulp. $H \& E$, bar $=50 \mu \mathrm{m}$.

\subsection{LC-MS Based Fingerprinting of Zebrafish Serum}

The collected serum from different groups of zebrafish (pure and adulterated honeytreated groups) was analyzed using LC-MS to investigate their serum fingerprints. Multivariate data analysis with OPLS was performed on the pre-processed LC-MS dataset to 
observe the discrimination among the samples. Validation of the multivariate calibration was performed using permutation testing. Figure $6 \mathrm{~A}$ shows the permutated model parameters and the $\mathrm{R}^{2}$ and $\mathrm{Q}^{2}$ values of the original model. The $\mathrm{X}$-axis indicates the correlation coefficients between original and permutated models and $\mathrm{Y}$-axis indicates the value of $\mathrm{R}^{2}$ and $\mathrm{Q}^{2}$. The original model exhibited higher values than those of the permutated models in the validation test. The $\mathrm{X}$-axis denotes the correlation between original and permuted data response, whereas the $\mathrm{Y}$-axis shows the $\mathrm{R}^{2}$ (the goodness-of-fit) and $\mathrm{Q}^{2}$ (predictability of the model). The permutation model is valid if the intercepts of $R^{2}$ and $Q^{2}$ are less than 0.4 and -0.05 , respectively [20]. The $R^{2}$ and $Q^{2}$ values in this study were 0.114 and -0.342 , respectively, which were in the acceptable range as shown in Figure 6A.

Figure $6 \mathrm{~B}$ shows the score scatter plot displaying the discrimination of the pure H. itama honey and sugar adulterated H. itama honey-treated group. All of the pure and sugar adulterated honey-treated group were separated alongside OPLS components 1 and 2 . While pure $H$. itama honey and cane sugar adulterated H. itama honey-treated group were shifted closer to each other in both OPLS-component 1 and 2 and support the $\mathrm{LD}_{50}$ results in which the cane sugar adulterated $H$. itama honey-treated group showed the lowest mortality rate after the pure H. itama honey-treated group. Inverted sugar adulterated-treated groups were shifted far from another honey-treated group alongside OPLS 1. This result is also in agreement with the result of a mortality rate that inverted sugar adulterated-treated group showed significantly $(p \leq 0.05)$ the lowest $\mathrm{LD}_{50}$ among other sugar adulterated-treated groups.


Figure 6. (A) Permutation results of partial least square-discriminant analysis (PLS-DA), (B) The OPLS score scatter plot of pure and adulterated $H$. itama honey using negative mode ionization in LC-MS analysis. PI = pure $H$. itama honey; IC $=H$. itama honey adulterated with cane sugar; IP $=H$. itama honey adulterated with palm sugar; ILC $=H$. itama honey adulterated with light corn syrup, and $\mathrm{II}=H$. itama honey adulterated with inverted sugar.

\subsection{Structural Elucidation Using MS/MS Fragmentation}

Metabolic profiling of zebrafish's serum force-feed by pure and adulterated H. itama honey was analyzed by multivariate statistical analysis. Data were obtained by UHPLC 
negative ion in order to establish and validate metabolomic profiling models. The MSMS fragmentation was used to elucidate the chemical structure of each parent ion, in combination with the search for the metabolites in HMDB, ChemSpider, and mzcloud. All fragmented MS spectra of each ion were compared to the NIST14 database library. By comparing all mass spectra, three biomarkers in negative ion modes were identified in Table 6.

Table 6. Tentative endogenous metabolites in the serum of zebrafish fed with pure and adulterated honey were identified using LC-MS/MS fragmentation based on negative mode ionization.

\begin{tabular}{|c|c|c|c|}
\hline Compound & M-H & MSMS Fragment Ions & Tentative Metabolites \\
\hline 1 & 236.00 & $\begin{array}{c}{\left[\mathrm{M}-\mathrm{CHO}_{2}\right]^{-} \text {at } m / z 192,\left[\mathrm{M}-\mathrm{CH}_{3} \mathrm{O}_{2}\right]^{-} \text {at } m / z 190,} \\
{\left[\mathrm{M}-\mathrm{C}_{2} \mathrm{H}_{5} \mathrm{O}_{2}\right]^{-} \text {at } m / z 176}\end{array}$ & S-Cysteinosuccinic acid \\
\hline 2 & 264.95 & $\begin{array}{c}{[\mathrm{M}-\mathrm{OH}]^{-} \text {at } m / z 246,\left[\mathrm{M}-\mathrm{CO}_{2}\right]^{-} \text {at } m / z 220,\left[\mathrm{M}-\mathrm{H}_{2}\right]^{-} \text {at } m / z} \\
218,\left[\mathrm{M}-\mathrm{CH}_{3} \mathrm{O}_{2}\right]^{-} \text {at } m / z 216,\left[\mathrm{M}-\mathrm{C}_{3} \mathrm{H}_{2} \mathrm{O}_{6} \mathrm{P}\right]^{-} \text {at } m / z 98 \\
{\left[\mathrm{M}-\mathrm{C}_{3} \mathrm{H}_{4} \mathrm{O}_{6} \mathrm{P}\right]^{-} \text {at } m / z 96}\end{array}$ & 2,3-Diphosphoglyceric acid \\
\hline 3 & 283.00 & $\begin{array}{c}{\left[\mathrm{M}-\mathrm{H}_{2} \mathrm{O}\right]^{-} \text {at } m / z 265,\left[\mathrm{M}-\mathrm{CO}_{2}\right]^{-} \text {at } m / z 239,\left[\mathrm{M}-\mathrm{CH}_{2} \mathrm{O}_{2}\right]^{-} \text {at }} \\
m / z 237,\left[\mathrm{M}-\mathrm{H}_{4} \mathrm{OS}\right]^{-} \text {at } m / z 231,\left[\mathrm{M}-\mathrm{CH}_{3} \mathrm{O}_{2}\right]^{-} \text {at } m / z 246\end{array}$ & Cysteinyl-Tyrosine \\
\hline
\end{tabular}

\section{Discussion}

In this study, the screening procedure was optimized and standardized in order to determine the toxic concentration of specific adulterated H. itama honey using the zebrafish — embryo and adult—model. The embryonic stages of zebrafish have provided several scorable endpoints in a toxicological model, especially in mortality and hatching rate [21]. The results of this research prove that the type and concentration of adulterants could have a significant impact on the mortality rate (\%) of the zebrafish embryo. The maximum $\mathrm{LC}_{50}$ was determined in order to monitor embryotoxicity at $96 \mathrm{hpf}$. The $\mathrm{LC}_{50}$ value for the toxicity of honey is indicated by the statistical estimation of the number of toxic substances $(\mathrm{mg})$ per body weight $(\mathrm{kg})$, which is required to be lethal to $50 \%$ of the population of the tested zebrafish embryos. According to the definition of $\mathrm{LC}_{50}$; the lower the $\mathrm{LC}_{50}$, the higher the mortality rate. Therefore, according to the results in Table 2, pure H. itama honey has higher $\mathrm{LC}_{50}$ and has significantly $(p \leq 0.05)$ less toxicity. Additionally, cane sugar is a less toxic sugar adulterant among other sugar adulterants, followed by palm sugar and light corn syrup. Inverted sugar in all adulterated percentages had the significantly $(p \leq 0.05)$ lowest $\mathrm{LC}_{50}$ value, which means higher toxicity compared to other sugar adulterants used in this paper. Soares, Amaral, Oliveira and Mafra [8] mentioned that adulterated honey with a high concentration of inverted syrup could cause harmful health effects, especially diabetes. Adulterated honey may lead to increased blood sugar, followed by the release of insulin hormone, causing insulin resistance and type II diabetes, abdominal weight gain and obesity, as well as a rise in the level of blood lipid and high blood pressure [22].

The development of zebrafish is categorized into four major stages: embryo, larvae, juvenile, and adult [23]. By $24 \mathrm{hpf}$, the embryos had functional circulatory systems, performed spontaneous twitching movements, and started pigmentation. Hence, the mortality rate investigation of zebrafish embryos began at $24 \mathrm{hpf}$. According to OECD (2012), the total percentage of the mortality rate was concluded by dead and unfertilized embryos, which revealed coagulated embryos, lack of somite formation, lack of heartbeat, and non-detachment of the tail. According to Figure 1, the mortality rate of embryos reached the maximum level at $96 \mathrm{hpf}$ in sugar adulterated honey groups. Adenan, et al. [24] stated that a higher concentration of H. itama honey could cause a higher incidence of lethality and abnormality at the early life stage of zebrafish embryos due to coagulation and absence of heartbeat in the zebrafish embryo. With regard to Figure 1, the mortality rate was recorded from $24 \mathrm{hpf}$ onward, and by increasing the concentration of pure H. itama honey from $4 \mathrm{mg} / \mathrm{mL}$ to $40 \mathrm{mg} / \mathrm{mL}$, a significant rise was experienced in the mortality rate 
of embryos $(p \leq 0.05)$. Exposure to $40 \mathrm{mg} / \mathrm{mL}$ of adulterated honey induced a significant $(p \leq 0.05)$ increase in mortality rate among different percentages $(1,2$, and $3 \%)$ of sugar adulterated honey (Figure 1). These results clearly showed that the number of dead embryos was correlated to the type of adulterants and the duration of treatment (hpf). In the liver of zebrafish, $\alpha$ and $\beta$ cells, which are responsible for increasing glycogenesis, are generated at $24 \mathrm{hpf}$ and matured at the same as in mammals [25]. Glycogenesis elevates the glucose level in embryos, which may cause an increase in the mortality rate in sugar adulterated H. itama honey, as is shown in Figure 1. In over-nutrition diets, such as high glucose concentration, the number of $\beta$ cells is boosted in both embryos and juvenile zebrafish [25]. In general, glucose may cause reactive oxygen species (ROS) production in the body through various ways in mitochondria, such as nicotinamide adenine dinucleotide phosphate (NADPH)-oxidase, sorbitol pathway, activated glycation, and insulin pathway [26]. High-glucose concentration triggered NADPH-oxidase [27] and caused a reduction of $\mathrm{O}_{2}$ to $\mathrm{O}_{2}{ }^{-}$and $\mathrm{H}_{2} \mathrm{O}_{2}$ to $\mathrm{OH}$ [26], as shown in Equation (1):

$$
2 \mathrm{O}_{2}+\mathrm{NADPH} \stackrel{\text { NADPH-Oxidase }}{\longrightarrow} 2 \mathrm{O}_{2}^{-}+\mathrm{NADP}^{+}+\mathrm{H}^{+}
$$

On the other hand, insulin may be secreted in response to the consumption of sugaradulterated honey. It would activate NADPH-oxidase located in the membrane enzyme system. Additionally, sugar consumption generates ROS in the body, which is a toxic element and can cause chronic diseases such as atherosclerosis, cancer, diabetes, hypertension, coronary artery diseases, and heart failure. Therefore, this may explain the high mortality rate of zebrafish embryos treated with sugar adulterated H. itama honey when adulteration percentages were increased, as seen in Figure 1. In addition, Jurczyk, et al. [28] mentioned that glucose level reached the highest peak in the embryo at $96 \mathrm{hpf}$ due to glucagon production, which stimulated gluconeogenesis and was expressed in enteroendocrine cells of the gut. This could be a reason the mortality rate (\%) of embryos treated with sugar adulterated $\mathrm{H}$. itama honey rose at $96 \mathrm{hpf}$, as seen in Figure 1 . The naturally produced glucose inside the body or adding glucose to the food can be harmful to zebrafish. These findings indicated that glucose toxicity in the zebrafish model may be used to suggest pathways with relevance to human diseases, especially diabetes.

Hatching is a critical point in a fish's life cycle that illustrates the developmental toxicology and biochemical mechanisms [29]. According to Figure 2a, control and pure H. itama honey followed the same hatching rate trend at $24-48 \mathrm{hpf}$. While zebrafish embryos treated with sugar adulterated $\mathrm{H}$. itama honey demonstrated a high early hatching rate at $24 \mathrm{hpf}$. It should be considered that early hatching at $24 \mathrm{hpf}$ was detrimental for zebrafish embryos since non-fully-developed larvae cannot survive exposure to the external environment. The mortality of individuals exposed to a high dose of adulterated honey may be explained by a high glucose load. These findings are concurrent to previous studies on rats that long-term consumption of any sugar syrup, such as sucrose or fructose, demonstrated a high mean total percentage of body fat and increased visceral fat pads, which led to hypercholesterolemia, hypertriglyceridemia, and hyperinsulinemia and caused animal death [30]. Therefore, these may be a reason for the high mortality rate of zebrafish by sugar adulterated H. itama honey when the dosage of adulterants was increased (Figure 2a). Furthermore, simple sugars, such as glucose and fructose-which naturally exist in pure honey-supply instant energy to human body cells and have a low glycemic index compared to sucrose as a complex sugar [31]. Pure honey showed significantly $(p \leq 0.05)$ lower toxicity in Figure 2a due to containing not only simple sugar (glucose and fructose) but also other nutrients, such as proteins, antioxidants, and minerals, which are essential to human health [32]. Zebrafish is a unique and vital model for the genetics and drug-driven heart failure due to the similarity of its heart to the human heart (Dahme, Katus, and Rottbauer, 2009). Therefore, in this paper, we developed and described the effect of pure and adulterated honey on the cardiac rate of zebrafish embryos. The regular heartbeat rate of zebrafish embryos varies between $120-180 \mathrm{bpm}$. A lower or higher heartbeat rate will 
cause embryo death. As has been demonstrated in Figure 2b, there was a slight decrease in the cardiac rate for pure H. itama honey compared to the control group that was due to the antioxidant activity of honey. Hence, honey, as a source of various antioxidant parameters, can reduce heartbeats to the normal level $(60-90 \mathrm{bpm})$, which is beneficial not only for patients suffering from tachycardia (heart rate $>100 \mathrm{bpm}$ ) but also hypertension and diabetes mellitus patients. There was a significant $(p \leq 0.05)$ increase in zebrafish embryo cardiac rate above the normal level at $96 \mathrm{hpf}(>180 \mathrm{bpm})$ when treated with sugar adulterated $H$. itama honey (Figure $2 b$ ). The zebrafish embryo treated with inverted sugar adulterated $H$. itama honey indicated the highest heartbeat rate compared to other sugar adulterated H. itama honey treated groups (Figure $2 b$ ). The rise in the heartbeat of embryos could be due to the presence of cardiac glycoside compound in sugar adulterated $H$. itama honey. According to Prassas and Diamandis [33], cardiac glycoside causes the inhibition of $\mathrm{Na}^{+} / \mathrm{K}^{+}$-ATPase and leads to raising the level of calcium ion to elevate the cardiac contractile force.

A model of force-feeding of adult zebrafish was appointed successfully to investigate the impact of pure and adulterated honey on the mortality rate (\%). Pure honey significantly $(p \leq 0.05)$ showed less toxic impact, which might be due to the existence of simpler sugars and high levels of antioxidants compared to adulterated honey (Table 5). The mortality of individuals exposed to a high dose of adulterated honey may be explained by a high glucose load. The $\mathrm{LD}_{50}$ findings in Table 5 were in agreement with our embryo toxicity test $\left(\mathrm{LC}_{50}\right)$ presented in Table 2 . Hence, glucose is either naturally produced in the body or added to foodstuff and can be detrimental to zebrafish. These findings persuaded us that glucose toxicity in the zebrafish model may identify pathways with relevance to human diseases, especially diabetes. Turanose, $3-\mathrm{O}-\alpha$-D-glucosyl-D-fructose is one of the sucrose isomers that naturally exists in honey. The 14-day acute and 13-week subchronic oral toxicological study of turanose showed no toxic effects on mice, and the $\mathrm{LD}_{50}$ value was greater than $10 \mathrm{~g} / \mathrm{kg}$ b.w (Chung 2017). The duration of honey consumption and the dosage may play a major role in the outcome of current results.

Histopathological examination is still considered the major standard in order to assess fibrosis and lesion occurrences in internal organs, such as the liver, kidney, spleen, etc. Typical histopathological alteration of sub-acute toxicity (14 days) is presented in Figure 5 individually for all non-treated and treated groups exposed to pure and adulterated honey. The liver is the first organ susceptible to poison and toxic substances. Any abnormality in the appearance of the liver is diet-dependent. In detail, the pure honey treated group showed mild foamy hepatocytes, while the remaining adulterated honey groups had vacuolation of the hepatocytes, affecting almost all hepatocytes. The adulterated honey groups also showed individual pyknotic nuclei scattered throughout the liver section. The liver of zebrafish treated with adulterated honey had huge hematomas. The hepatocytes of all control zebrafish appeared normal. The liver sections of all honey-treated (pure and adulterated) groups showed some degree of blood vessel congestion. The pure honey groups had relatively mild congestion, while the adulterated groups showed severe congestion. The long-term (14 days) exposure to adulterated honey led to the prolonged generation of reactive oxygen species (ROS), which caused hepatic injury, and confirmed a higher mortality rate in the adulterants treated group (Figure 5). Once a poison is ingested, it is absorbed from the intestine and is brought to the liver for detoxification. This results in congestion in the liver and also changes in liver architecture, followed by loss of tissue function as a response to ROS. On the contrary, there was no alteration in liver tissue of the control group (Figure 5). Ranneh, et al. [34] indicated a reduction of inflammatory cell infiltration in the liver of Sprague-Dawley rats when supplemented with stingless bee honey (Trigona). However, in current findings, only foamy hepatocytes and pyknotic nuclei were present in the liver of zebrafish fed with pure honey (Figure 5). Such conflicting results might depend on the type of toxic compound and its concentration, animal species, exposure time, etc. [35]. Among these pathological changes, hepatocytes initially showed vacuolation then necrosis in the form of the pyknotic nucleus, which was indicated in 
Figure 5. In this regard, Ni, et al. [36] suggested vacuole formation in the hepatocyte might be due to interference in lipid metabolism followed by fat filtration in the liver of zebrafish, while hepatocyte necrosis and apoptosis might cause the pyknotic nucleus. From the liver, the poison circulates throughout the body. However, the poison is eventually removed from the body through the kidney. Hepatocyte lesion reduces liver efficacy to detoxify the poison leading to congestion and degenerative changes in the kidneys, as observed in Figure 5. Lesions in the kidneys were observed mostly in the tubules, the epithelial lining, and the interstitial tissue, particularly the blood vessels. The tubular epithelium showed various degenerative changes, including cytoplasmic vacuolation, cytoplasmic destruction, and pyknotic nuclei. The blood vessels showed various degrees of congestion as a result of hypercellular activities in the kidney head. Regarding the tubular vacuolation (mild to moderate) in the adulterated-honey treated group, Kiss and Hamar [37] emphasized tubular vacuolization as a sign of toxicity. However, experimental studies support sugar intake as one of the major factors causing kidney injury. With regard to this, Johnson, et al. [38] found the administration of a $60 \%$ fructose diet to rats induces renal hypertrophy with tubular cell proliferation and low-grade tubulointerstitial injury. Osmotically active compounds, such as some sugars, often result in "osmotic nephrosis", which appears as cytoplasmic vacuolation of renal tubule epithelium and risk factors for the development of pre-existing chronic kidney diseases (CKD).

The large red pulp appearing in the spleen of the adulterated treated group (Figure 5) could be due to congestion of blood cells by toxic compounds from adulterants. In this regard, Bronte and Pittet [39] mentioned that congestion in the spleen leads to blood accumulation in the red pulp, which, consequently, appears to be much more extensive than when the organ is first emptied of its blood, leading to the death of the fish.

The three metabolites were identified through LC-MS/MS analysis from the serum of zebrafish, as shown in Table 6, which were force-fed with pure and sugar adulterated H. itama honey. The identified metabolites were: (1) S-Cysteinosuccinic acid from pure H. itama group, (2) 2,3-Diphosphoglyceric acid from adulterated H. itama with cane sugar, and (3) Cysteinyl-Tyrosine from adulterated H. itama with palm sugar. These identified metabolites were counted as endogenous biomarkers while consuming pure or adulterated honey. S-Cysteinosuccinic acid was detected in the pure H. itama honey-treated group (Table 6). This endogenous compound was also observed at low levels in the urine of Sprague-Dawley rats with diet-induced hyperlipidemia (high-fat diet) compared with the control group [40]. In another study, Chakrabarti and Denniel [41] reported the toxicity of S-conjugated Cysteine (S-[(1 and 2)-phenyl-2-hydroxyethyl]-cysteine) in the rat. They observed a sequence of systematic toxic responses in renal proximal tubules of the rat. In addition, this research suggested that stimulation of lipid peroxidation mitochondria due to the S-conjugated Cysteine produced malondialdehyde (MDA) exposure in renal proximal tubules would lead to cell death. Therefore, it can be concluded that the S-conjugated Cysteine compound can alter the mitochondrial function as a result of lipid peroxidation. This function alteration leads to cell death due to the consequent loss of cellular energy supplies as a result of $\mathrm{LD}_{50}$ (Table 5). Furthermore, the fairly vacuolated accrued renal tubules of the pure H. itama honey-treated group in Figure 5 could be due to the accumulation of this metabolite in zebrafish. 2,3-Diphosphoglyceric acid, known as 2,3-DPG, was detected from cane sugar adulterated H. itama honey-treated groups (Table 6). This biomarker is present in human blood at high levels and acts as an allosteric effector in order to release more oxygen from haemoglobin and leads oxygenation to the tissue [42]. Macdonald [43] proposed that 2,3-DPG accumulation might be due to hyperthyroidism and an increased rate of glycolysis. Additionally, a high accumulation of 2,3-DPG has been reported in patients with congestive cardiac failure, chronic renal failure, and cirrhosis of the liver [43]. Since this compound has been identified in treated zebrafishes with cane sugar adulterated $H$. itama honey, the liver failure as a result of huge hematomas, significant degenerative changes in the kidney (Figure 5), and lower $\mathrm{LD}_{50}$ values (Table 5) in comparison to pure $H$. itama could be explained. Furthermore, Cysteinyl-Tyrosine was detected in the serum of 
zebrafishes that were treated with H. itama honey adulterated with palm sugar (Table 6). Cysteinyl-tyrosine covalent could be found in cysteine deoxygenase (CDO), galactose oxidase, and NirA [44-46]. The Cys and Tyr concentration alteration in blood serum is associated with insulin resistance. Therefore, it is a noticeable biomarker in asymptomatic syndromes, such as adiposity, hyperglycemia, hypertension, and dyslipidemia [47]. These symptoms can be related to pathological changes in the liver of zebrafish treated with adulterated H. itama honey, as shown in Figure 5.

However, the current study was the first in vivo toxicity study of pure and adulterated H. itama honey on zebrafish - embryo and adult; thus, there is a lack of established protocol in the zebrafish model, causing an inability to make significant comparisons among various studies.

\section{Materials and Methods}

\subsection{Materials}

The cane sugar, palm sugar, and light corn syrup were attained from Malayan Sugar Manufacturing Prai Bhd (Sungai Buloh, Selangor, Malaysia). Nek Nor and Phoon Huat \& Co. Pte. Ltd. (AEON Supermarket, Kuala Lumpur, Malaysia), respectively. With regard to force-feed apparatuses, a 22-G soft tube catheter was purchased from SAI Infusion Technologies (Chicago, USA) and a $1 \mathrm{~mL}$ luerlok syringe was procured from Hamilton (Reno, Nevada). Formalin, ethanol, and glacial citric acid were procured from Sigma Chemical Co. (St. Louis, MO, USA). Absolute methanol and formic acid (HPLC grade) were purchased from Thermo Fisher Scientific (Pittsburg, PA, USA). Distilled water was passed through a Milli-Q water purification system (Millipore, Bedford, MA, USA) for the preparation of LC mobile phases.

\subsection{Methods}

\subsubsection{Sample Collection}

The pure honey sample was collected fresh from a local honey seller located at Gong Beris, Terengganu, Malaysia from an acacia environment-Acacias. The honey sample was kept at $4{ }^{\circ} \mathrm{C}$ during the transportation and upon arrival at the lab. The sampling method of H. itama honey was adopted from the Department of Standard Malaysia (Malaysian Standard, 2017).

\subsubsection{Brix Analysis}

Total soluble solid was measured at $25{ }^{\circ} \mathrm{C}$ using a digital refractometer (ATAGO, Tokyo, Japan). Approximately $0.3 \mathrm{~mL}$ of honey was placed onto the prism surface, and the reading was recorded as Brix [48].

\subsubsection{Honey Adulteration}

Pure honey was filtered by 60 mesh screens in order to eliminate impurities and was stored in the dark at $4{ }^{\circ} \mathrm{C}$ for further analysis. Before the analysis, the honey sample was thermostated to room temperature $\left(25^{\circ} \mathrm{C}\right)$ and homogenized by manual stirring thoroughly for at least $3 \mathrm{~min}$. Sugar adulterants (light corn sugar, cane sugar, inverted sugar, and palm sugar) each at $1 \%, 2 \%$, and $3 \%(w / w)$ of total volume were added to the pure H. itama honey.

\subsubsection{Embryotoxicity Study in Danio Rerio}

The zebrafish embryotoxicity assay was carried out based on the Organization for Economic Cooperation and Development (OECD) guideline for fish embryo toxicity (da Silva, Gauche, Gonzaga, Costa, and Fett) test (OECD, 2012). Wild-type zebrafish embryos were procured from Danio Assay Laboratories Sdn.Bhd (Serdang, Selangor, Malaysia).

\subsubsection{Toxicity Test}

Different concentrations $(4,8,16,24,32$, and $40 \mathrm{mg} / \mathrm{mL})$ of adulterated honey and pure honey (as control) were set in 96-well plates (Thermo Scientific TM, New Hamshire, UK). 
Fertilized zebrafish eggs were collected within $3 \mathrm{~h}$ of postfertilization (hpf). The embryo was pipetted into each well by using a micropipette (Eppendorf, Hamburg, Germany), i.e., four replications $(n=8)$. Embryo medium E3 was used as a positive control. The medium was not renewed throughout the experiment. Embryo development was observed at 24, 48,72 , and $96 \mathrm{hpf}$ with an inverted microscope (Nikon, Eclipse TS100, Chicago, IL, USA) to assess mortality. Mortality was scored by two complementary criteria, including the coagulation of embryos at early stages ( 24 and $48 \mathrm{hpf}$ ), and deformity sufficiently severe (e.g., lack of somite and lack of heartbeat) to be considered effectively lethal (OECD, 2012). The numbers of embryos with lethal effects were scored at $96 \mathrm{hpf}$ in all test groups. The mortality rate (\%) of embryos was determined using Equation (2) as below:

$$
\text { Mortality rate }(\%)=\text { No. of dead embryos } / \text { Total embryos } \times 100
$$

\subsubsection{Evaluation of Zebrafish Embryos Hatching Rate}

The zebrafish embryo hatch rate was observed at $24,48,72$, and $96 \mathrm{hpf}$ with an inverted microscope (Nikon, Eclipse TS100, Chicago, IL, USA). The hatching rate of embryos was determined as the rupture of the chorion for release of larvae in the comparison between different pure and adulterated honey (3\%). The hatching rate (\%) was calculated using Equation (3) as follow:

Percentage of hatchability $(\%)=$ No. of hatched embryos $/$ total number of incubated embryos $\times 100$

\subsubsection{Evaluation of Zebrafish Embryo and Larvae Heartbeats}

The heartbeat of zebrafish embryos and larvae at $24,48,72$, and $96 \mathrm{hpf}$ was examined after treatment with pure and adulterated honey (3\%). The cardiac toxicity was assessed by manually counting each embryo and larvae heartbeat within 1 min by direct visual observation of the zebrafish embryo and larval cardiac ventricles by using an inverted microscope connected to a computer and camera device using objective lenses with $4 \times$, $10 \times$, and $40 \times$ magnification, and the heart rate was counted per minute.

\subsubsection{Pre-and Post-Treatment Zebrafish Maintenance}

The aim of the adult zebrafish toxicity test is to find out the critical dose that kills $50 \%$ of zebrafishes (LD50). It would lead to discovering the safe dose in which the zebrafish will survive and guarantee a specific concentration of adulterated honey safe for human consumption.

The study was approved under the Ethical Use of Animals (IACUC) with Reference No. AUP-R059/2018. All tested fishes were selected from a laboratory population from a single stock. The fishes were acclimated for two weeks prior to the test under conditions of water quality and illumination similar to those of the test condition OECD [18]. Force-feeding or oral administration was obtained by Collymore, et al. [49] for this study with slight modification. Briefly, adult zebrafishes with an average weight of $0.5-0.8 \mathrm{~g}$, an average length of $24.50 \mathrm{~mm}$, and 4 months old were purchased from Danio Assay Laboratories Sdn. Bhd. (Serdang, Selangor, Malaysia). Zebrafishes were fed daily with fish micropellet and live food (Artemia) and maintained in aquaria at the temperature of $28^{\circ} \mathrm{C}$ with a 14:10 $\mathrm{h}$ light-dark cycle. Zebrafishes were fasted for $12 \mathrm{~h}$ prior to force-feeding [50] in order to evacuate the intestinal bulb. On the day of force-feeding, fifteen randomly selected zebrafish (Danio rerio) were force-fed with different concentrations of honey. It was suggested that at least seven fish must be used for each test concentration and control, therefore, a total of 15 fish were used in the present study. The selection of adulterant's concentration was based on the result obtained from the toxicity test on zebrafish embryos. The $\mathrm{LD}_{50}$ value was expressed in terms of the weight of the test substance per unit weight of the test animal (mg/kg) [51] for all three types of toxicity tests (acute, prolong-acute, and sub-acute). The median lethal dose $\left(\mathrm{LD}_{50}\right)$ is a statistically derived single dose of a substance that can be expected to cause death in $50 \%$ of animals when administered by the oral route. 


\subsubsection{Design of The Acute Toxicity Test}

An acute oral toxicity test was performed to observe the short-term administration of honey according to the guidelines of OECD for testing of chemicals, TG 423 with slight modifications [51]. It measures the toxic effects of honey, such as lethality, occurring from oral administration of a single dose of honey. For the test group, fixed doses of pure H. itama honey with a concentration of 1,5 , and $10 \mathrm{mg} / \mathrm{g}$ body weight (BW) of adult zebrafish were force-fed only once, and the control group was force-fed with distilled water. Meanwhile, mortality was observed after $24 \mathrm{~h}$.

\subsubsection{Design of The Prolong-Acute Toxicity Test}

The prolong-acute toxicity test of pure $\mathrm{H}$. itama honey on the adult zebrafish was carried out for 3 days (72 h) according to Khedkar, et al. [52] with slight modification. Dosing for the prolong-acute procedure was reduced to 3,1 , and $0.5 \mathrm{mg} / \mathrm{g}$ BW of the zebrafish. The mortality rate (\%) of zebrafishes was recorded at the end of $72 \mathrm{~h}$.

\subsubsection{Design of The Sub-Acute Toxicity Test}

To determine the long term effect of the honey toxicity on the survival rate of adult zebrafish, they were exposed to the sub-acute toxicity test with different concentrations of pure and adulterated honey solutions for 14 days according to Ni, Peng, Gao, Ji, Ma, Li and Jiang [36] with slight modification. Multi force-feeding was applied regarding a hypothesis by Olsen, et al. [53] that adult zebrafish would be capable of pancreatic regeneration. To prevent regeneration and allow the toxicity effect to occur, zebrafishes were force-fed at days $1,5,9$, and 13 with a dose of $0.1,0.5$, and $1 \mathrm{mg} / \mathrm{g} B W$ of the zebrafish. Mortality rate $(\%)$ was recorded on day 14 , and safe concentrations at which more zebrafishes survived were chosen as a safe dose.

\section{Histology}

Various organs (liver, kidney, and spleen) of zebrafish underwent fixation and embedding steps for observation process by a skilled pathologist who was blind to the study in order to evaluate the pathological changes and scored inflammation.

\subsection{LC-MS-Q TOF Based Fingerprinting}

On day 14 after the sub-acute toxicity test, the zebrafish were fasted for $24 \mathrm{~h}$ prior to blood withdrawal. While previous studies developed various protocols for blood collecting, such as lateral incision in the dorsal aorta region, decapitation, and tail ablation, which required the animal to be sacrificed [10], we proceeded with blood collection from the heart of live zebrafish through the gills. The blood was withdrawn from the heart using a syringe, the needle was pushed carefully under the gill, and around $10 \mu \mathrm{L}$ of the blood was withdrawn. The zebrafish blood was centrifuged (Thermo ScientificTM, New Hamshire, UK) under 10,000 rpm for $10 \mathrm{~min}$ to separate the serum (supernatant) from the debris (precipitate). The serum was immersed in liquid nitrogen for enzyme inactivation. Subsequently, $5 \mu \mathrm{L}$ of the serum was added into $250 \mu \mathrm{L}$ of water: methanol $(1: 1, v / v)$, vortexed and centrifuged at 10,000 rpm for $10 \mathrm{~min}$. Then, $200 \mu \mathrm{L}$ of the supernatant was transferred into the LC-MS insert vial and stored at $-80^{\circ} \mathrm{C}$ prior to the LC-MS /MS analysis. The prepared samples were subjected to metabolite identification using an Agilent 1290 Infinity LC system coupled with Agilent 6530 Accurate-Mass Quadrupole-Time-of-Flight (QTOF) mass spectrometry (Agilent, Santa Clara, CA, USA). The serum sample (10 $\mu \mathrm{L})$ was injected into the UPLC-Q-TOF-MS system. A C18 column (Phenomenex, Torrance, CA, USA) of $100 \AA$, and $250 \times 4.6 \mathrm{~mm}, 5 \mu$ ) was used as a stationary phase. The mobile phase was composed of solvent $\mathrm{A}\left(100 \% \mathrm{CH}_{3} \mathrm{OH}\right)$ and solvent $\mathrm{B}$ (a mixture of $\mathrm{H}_{2} \mathrm{O}$ and $0.1 \% \mathrm{CH}_{2} \mathrm{O}_{2}$ ). The run started initially at $95 \%$ of solvent $\mathrm{A}$ and $5 \%$ of solvent $\mathrm{B}$ for $1 \mathrm{~min}$, then from $95 \%$ to $64 \%$ of solvent $A$ and $5 \%$ to $36 \%$ of solvent B in 2-16 min, followed by $0 \%$ of solvent A and $100 \%$ solvent B at $17-27$ min. The final run was $95 \%$ of solvent A and 
$5 \%$ of solvent B in $28-33 \mathrm{~min}$. The total run time used was $33 \mathrm{~min}$. Electrospray ionization with negative mode without fragmentation was applied.

The data was pre-processed using ACD/Spec Manager v.12.00 lab software (Advanced Chemistry Development, Inc., Toronto, Canada) and converted into a CDF file. The mass net CDF files were further pre-processed using Rstudio (Boston, MA, USA) [54] to extract all the related information from the raw data and convert it to a data matrix, which includes systematic noise filtering, automatic peak detection, baseline correction, data binning, deconvolution, and chromatographic alignment. Finally, the data were summarized into an Excel sheet prior to multivariate data analysis [55].

\subsection{Statistical Analysis}

Following recommendations in the OECD guideline (OECD, 2012), probit analysis was used to determine $\mathrm{LC}_{50}$ and $\mathrm{LD}_{50}$. All statistical analyses were expressed as mean \pm standard error of the mean using GraphPad Prism 8.0 for Macintosh (GraphPad Prism, La Jolla, CA, USA) to calculate $\mathrm{LC}_{50}$ and $\mathrm{LD}_{50}$ based on the concentration-response relationship. To distinguish the statistically significant difference between treatment and control groups, one-way ANOVA followed by Tukey's test was performed. $p \leq 0.05$ was considered significant. For chemometrics analysis, the pre-processed raw data were imported using SIMCA P + 14.0 software (version 14.0, Umetrics, Umea, Vasterbotten, Sweden) and a model was developed using the OPLS method. Subsequently, the model was validated through a permutation test. Finally, the score scatters were developed to identify potential endogenous metabolites. All experiments were conducted in triplicate.

\section{Conclusions}

According to a significant $(p \leq 0.05)$ increase in mortality rate $(\%)$ of zebrafishembryo and adult-in sugar adulterated H. itama honey, our experiment proved that adulterated $H$. itama honey is not beneficial toward human health, while pure honey does not show any significant $(p \leq 0.05)$ cardiotoxicity effect. However, the novel information of this study revealed the dose-dependent effect of adulterated honey on the heartbeat and hatching rate of zebrafish embryos. The tissue modification of adult zebrafish may ring the bell for upcoming research on human tissue alteration due to the consumption of adulterated honey. The results of this study demonstrate that adulterated honey possesses some endogenous compounds that are harmful toward the zebrafish body. Considering all approaches, these results might be a promising candidate for early diagnostic biomarkers that can prevent the development of metabolic diseases, such as diabetes (type 1 and 2). The findings of this study can be extrapolated to human health, and it can be concluded that adulterated honey only enhances honey flavor and acceptability by consumers. Since this is the first research on the toxicity effect of sugar adulterated $H$. itama honey in an aquatic system, these findings can be used to provide some guidance regarding risk assessment and an acceptable safe level of adulterants. In order to gain valuable insight regarding the toxicity of adulterated honey on internal organs, a more in-depth study of the embryo and juvenile zebrafish is warranted for future studies.

Author Contributions: Conceptualization, J.S. and R.F.; data curation, R.F.; formal analysis, R.F. and A.K.; funding acquisition, J.S.; investigation, R.F.; methodology, R.F., J.S., A.F.A.R. and S.A.; project administration, J.S.; resources, J.S.; software, A.K., R.F. and S.A.; supervision, J.S. A.K., R.S. and A.F.A.R.; validation, J.S.; visualization, R.F. and A.A.B.; writing-original draft preparation, R.F.; writing-review and editing, J.S., R.F. and A.A.B. All authors have read and agreed to the published version of the manuscript.

Funding: This research was funded by the Ministry of Higher Education (MOHE), Malaysia with grant number (FRGS-MRSA/1/2016/STG01/UPM/01/1).

Institutional Review Board Statement: The study was conducted according to the guidelines of the Declaration of Helsinki and approved by the Institutional Review Board of Institutional Animal Care and Use Committee (IACUC), Universiti Putra Malaysia (AUP-R059/2018). 
Informed Consent Statement: Not applicable.

Data Availability Statement: The data presented in this study are available on request from the corresponding author. The data are not publicly available due to the rules and regulations of University Putra Malaysia (UPM).

Acknowledgments: The authors also would like to thank the Ministry of Higher Education Malaysia (MOHE) for the HICoE rendered to the Institute of Tropical Agriculture and Food Security (ITAFoS), University Putra Malaysia (UPM).

Conflicts of Interest: The authors declare no conflict of interest.

Sample Availability: Samples of the compounds are available from the authors.

\section{References}

1. Codex Alimentarius Commission. Revised Codex Standard for Honey. Codex Stan 2001, 12-1981 FAO; WHO: Geneva, Switzerland, 2001.

2. Tumbas, V.T.; Vulić, J.J.; Čanadanović-Brunet, J.M.; Đilas, S.M.; Ćetković, G.S.; Stajčić, S.S.; Štajner, D.I.; Popović, B.M. Antioxidant and sensorial properties of acacia honey supplemented with prunes. Acta Period. Technol. 2012, 43, 293-304. [CrossRef]

3. Rao, P.V.; Krishnan, K.T.; Salleh, N.; Gan, S.H. Biological and therapeutic effects of honey produced by honey bees and stingless bees: A comparative review. Rev. Bras. Farmacogn. 2016, 26, 657-664. [CrossRef]

4. Shamsudin, S.; Selamat, J.; Sanny, M.; AR, S.B.; Jambari, N.N.; Khatib, A. A comparative characterization of physicochemical and antioxidants properties of processed Heterotrigona itama honey from different origins and classification by chemometrics analysis. Molecules 2019, 24, 3898. [CrossRef]

5. Puscas, A.; Hosu, A.; Cimpoiu, C. Application of a newly developed and validated high-performance thin-layer chromatographic method to control honey adulteration. J. Chromatogr. A 2013, 1272, 132-135. [CrossRef]

6. Fakhlaei, R.; Selamat, J.; Khatib, A.; Razis, A.F.A.; Sukor, R.; Ahmad, S.; Babadi, A.A. The toxic impact of honey adulteration: A review. Foods 2020, 9, 1538. [CrossRef] [PubMed]

7. Fuhrman, J. The hidden dangers of fast and processed food. Am. J. Lifestyle Med. 2018, 12, 375-381. [CrossRef]

8. Soares, S.; Amaral, J.S.; Oliveira, M.B.P.; Mafra, I. A comprehensive review on the main honey authentication issues: Production and origin. Compr. Rev. Food Sci. Food Saf. 2017, 16, 1072-1100. [CrossRef]

9. Dayal, N.; Thakur, M.; Soparkar, A.; Doctor, M.; Patil, P.; Joshi, D. Effective method to deliver test substance in adult zebrafish. Int. J. Adv. Res. 2016, 4, 543-551. [CrossRef]

10. Sobrino-Gregorio, L.; Vilanova, S.; Prohens, J.; Escriche, I. Detection of honey adulteration by conventional and real-time PCR. Food Control 2019, 95, 57-62. [CrossRef]

11. Wang, S.; Guo, Q.; Wang, L.; Lin, L.; Shi, H.; Cao, H.; Cao, B. Detection of honey adulteration with starch syrup by high performance liquid chromatography. Food Chem. 2015, 172, 669-674. [CrossRef]

12. Ruiz-Matute, A.I.; Rodríguez-Sánchez, S.; Sanz, M.L.; Martínez-Castro, I. Detection of adulterations of honey with high fructose syrups from inulin by GC analysis. J. Food Compos. Anal. 2010, 23, 273-276. [CrossRef]

13. Chen, Q.; Qi, S.; Li, H.; Han, X.; Ouyang, Q.; Zhao, J. Determination of rice syrup adulterant concentration in honey using three-dimensional fluorescence spectra and multivariate calibrations. Spectrochim. Acta Part A Mol. Biomol. Spectrosc. 2014, 131, 177-182. [CrossRef]

14. Li, S.; Shan, Y.; Zhu, X.; Zhang, X.; Ling, G. Detection of honey adulteration by high fructose corn syrup and maltose syrup using Raman spectroscopy. J. Food Compos. Anal. 2012, 28, 69-74. [CrossRef]

15. Qu, L.; Jiang, Y.; Huang, X.; Cui, M.; Ning, F.; Liu, T.; Gao, Y.; Wu, D.; Nie, Z.; Luo, L. High-throughput monitoring of multiclass syrup adulterants in honey based on the oligosaccharide and polysaccharide profiles by MALDI mass spectrometry. J. Agric. Food Chem. 2019, 67, 11256-11261. [CrossRef]

16. Arroyo-Manzanares, N.; García-Nicolás, M.; Castell, A.; Campillo, N.; Viñas, P.; López-García, I.; Hernández-Córdoba, M. Untargeted headspace gas chromatography-Ion mobility spectrometry analysis for detection of adulterated honey. Talanta 2019, 205, 120123. [CrossRef]

17. Du, B.; Wu, L.; Xue, X.; Chen, L.; Li, Y.; Zhao, J.; Cao, W. Rapid screening of multiclass syrup adulterants in honey by ultrahighperformance liquid chromatography/quadrupole time of flight mass spectrometry. J. Agric. Food Chem. 2015, 63, 6614-6623. [CrossRef]

18. Wang, J.; Xue, X.; Du, X.; Cheng, N.; Chen, L.; Zhao, J.; Zheng, J.; Cao, W. Identification of acacia honey adulteration with rape honey using liquid chromatography-electrochemical detection and chemometrics. Food Anal. Methods 2014, 7, $2003-2012$. [CrossRef]

19. Benchoula, K.; Khatib, A.; Quzwain, F.; Che Mohamad, C.A.; Wan Sulaiman, W.M.A.; Abdul Wahab, R.; Ahmed, Q.U.; Abdul Ghaffar, M.; Saiman, M.Z.; Alajmi, M.F. Optimization of hyperglycemic induction in zebrafish and evaluation of its blood glucose level and metabolite fingerprint treated with Psychotria malayana jack leaf extract. Molecules 2019, 24, 1506. [CrossRef] [PubMed]

20. Haq, M.; Gonzalez, N.; Mintz, K.; Jaja-Chimedza, A.; De Jesus, C.L.; Lydon, C.; Welch, A.Z.; Berry, J.P. Teratogenicity of ochratoxin A and the degradation product, ochratoxin $\alpha$, in the zebrafish (Danio rerio) embryo model of vertebrate development. Toxins 2016, 8, 40. [CrossRef] [PubMed] 
21. Haffner, S.M.; Valdez, R.A.; Hazuda, H.P.; Mitchell, B.D.; Morales, P.A.; Stern, M.P. Prospective analysis of the insulin-resistance syndrome (syndrome X). Diabetes 1992, 41, 715-722. [CrossRef]

22. Parichy, D.M.; Elizondo, M.R.; Mills, M.G.; Gordon, T.N.; Engeszer, R.E. Normal table of postembryonic zebrafish development: Staging by externally visible anatomy of the living fish. Dev. Dyn. 2009, 238, 2975-3015. [CrossRef]

23. Adenan, M.N.H.; Yazan, L.S.; Christianus, A.; Hashim, N.F.M.; Harun, A.R.; Halim, N.H.A.; Sani, M.Z.; Rahim, K.A. Effects of Kelulut honey from Trigona sp. on zebrafish (Danio rerio) embryo that mimics human embryonic development. J. Cell Anim. Biol. 2018, 12, 5-14.

24. Maddison, L.A.; Chen, W. Modeling pancreatic endocrine cell adaptation and diabetes in the zebrafish. Front. Endocrinol. 2017, 8 , 9. [CrossRef]

25. Prasad, K.; Dhar, I. Oxidative stress as a mechanism of added sugar-induced cardiovascular disease. Int. J. Angiol. 2014, 23, 217-226. [PubMed]

26. Bonnefont-Rousselot, D. Glucose and reactive oxygen species. Curr. Opin. Clin. Nutr. Metab. Care 2002, 5, 561-568. [CrossRef] [PubMed]

27. Jurczyk, A.; Roy, N.; Bajwa, R.; Gut, P.; Lipson, K.; Yang, C.; Covassin, L.; Racki, W.J.; Rossini, A.A.; Phillips, N. Dynamic glucoregulation and mammalian-like responses to metabolic and developmental disruption in zebrafish. Gen. Comp. Endocrinol. 2011, 170, 334-345. [CrossRef] [PubMed]

28. Li, K.; Wu, J.-Q.; Jiang, L.-L.; Shen, L.-Z.; Li, J.-Y.; He, Z.-H.; Wei, P.; Lv, Z.; He, M.-F. Developmental toxicity of 2,4dichlorophenoxyacetic acid in zebrafish embryos. Chemosphere 2017, 171, 40-48. [CrossRef]

29. Suhana Samat, F.K.E.; Razak, A.A.; Hussein, F.N.; Ismail, W.I.W. Adulterated honey consumption can induce obesity, increase blood glucose level and demonstrate toxicity effects. Sains Malays. 2018, 47, 353-365.

30. Al-Waili, N.; Salom, K.; Al-Ghamdi, A.; Ansari, M.J. Antibiotic, pesticide, and microbial contaminants of honey: Human health hazards. Sci. World J. 2012, 2012, 930849. [CrossRef]

31. Bogdanov, S.; Jurendic, T.; Sieber, R.; Gallmann, P. Honey for nutrition and health: A review. J. Am. Coll. Nutr. 2008, 27, 677-689. [CrossRef]

32. Prassas, I.; Diamandis, E.P. Novel therapeutic applications of cardiac glycosides. Nat. Rev. Drug Discov. 2008, 7, 926-935. [CrossRef] [PubMed]

33. Ranneh, Y.; Akim, A.M.; Ab Hamid, H.; Khazaai, H.; Fadel, A.; Mahmoud, A.M. Stingless bee honey protects against lipopolysaccharide induced-chronic subclinical systemic inflammation and oxidative stress by modulating Nrf2, NF- $\mathrm{kB}$ and p38 MAPK. Nutr. Metab. 2019, 16, 15. [CrossRef]

34. Paris-Palacios, S.; Biagianti-Risbourg, S.; Vernet, G. Biochemical and (ultra) structural hepatic perturbations of Brachydanio rerio (Teleostei, Cyprinidae) exposed to two sublethal concentrations of copper sulfate. Aquat. Toxicol. 2000, 50, 109-124. [CrossRef]

35. Ni, H.; Peng, L.; Gao, X.; Ji, H.; Ma, J.; Li, Y.; Jiang, S. Effects of maduramicin on adult zebrafish (Danio rerio): Acute toxicity, tissue damage and oxidative stress. Ecotoxicol. Environ. Saf. 2019, 168, 249-259. [CrossRef] [PubMed]

36. Kiss, N.; Hamar, P. Histopathological evaluation of contrast-induced acute kidney injury rodent models. BioMed Res. Int. 2016, 2016, 3763250. [CrossRef] [PubMed]

37. Johnson, R.J.; Sanchez-Lozada, L.G.; Nakagawa, T. The effect of fructose on renal biology and disease. J. Am. Soc. Nephrol. 2010, 21, 2036-2039. [CrossRef]

38. Bronte, V.; Pittet, M.J. The spleen in local and systemic regulation of immunity. Immunity 2013, 39, 806-818. [CrossRef] [PubMed]

39. Chen, H.; Yuan, B.; Miao, H.; Tan, Y.; Bai, X.; Zhao, Y.-Y.; Wang, Y. Urine metabolomics reveals new insights into hyperlipidemia and the therapeutic effect of rhubarb. Anal. Methods 2015, 7, 3113-3123. [CrossRef]

40. Chakrabarti, S.K.; Denniel, C. S-[(1 and 2)-phenyl-2-hydroxyethyl]-cysteine-induced cytotoxicity to rat renal proximal tubules. Toxicol. Appl. Pharmacol. 1996, 137, 285-294. [CrossRef]

41. Kim, H.; Kosinski, P.; Kung, C.; Dang, L.; Chen, Y.; Yang, H.; Chen, Y.-S.; Kramer, J.; Liu, G. A fit-for-purpose LC-MS/MS method for the simultaneous quantitation of ATP and 2,3-DPG in human $\mathrm{K}^{2}$ EDTA whole blood. J. Chromatogr. B 2017, 1061, 89-96. [CrossRef]

42. Macdonald, R. Red cell 2,3-diphosphoglycerate and oxygen affinity. Anaesthesia 1977, 32, 544-553. [CrossRef] [PubMed]

43. Ito, N.; Phillips, S.E.; Stevens, C.; Ogel, Z.B.; McPherson, M.J.; Keen, J.N.; Yadav, K.D.; Knowles, P.F. Novel thioether bond revealed by a $1.7 \AA$ crystal structure of galactose oxidase. Nature 1991, 350, 87-90. [CrossRef]

44. Schnell, R.; Sandalova, T.; Hellman, U.; Lindqvist, Y.; Schneider, G. Siroheme-and [Fe4-S4]-dependent NirA from Mycobacterium tuberculosis is a sulfite reductase with a covalent Cys-Tyr bond in the active site. J. Biol. Chem. 2005, 280, 27319-27328. [CrossRef]

45. Simmons, C.R.; Liu, Q.; Huang, Q.; Hao, Q.; Begley, T.P.; Karplus, P.A.; Stipanuk, M.H. Crystal structure of mammalian cysteine dioxygenase a novel mononuclear iron center for cysteine thiol oxidation. J. Biol. Chem. 2006, 281, 18723-18733. [CrossRef]

46. Mohorko, N.; Petelin, A.; Jurdana, M.; Biolo, G.; Jenko-Pražnikar, Z. Elevated serum levels of cysteine and tyrosine: Early biomarkers in asymptomatic adults at increased risk of developing metabolic syndrome. BioMed Res. Int. 2015, $2015,418681$. [CrossRef] [PubMed]

47. Shamsudin, S.; Selamat, J.; Sanny, M.; Abd Razak, S.-B.; Jambari, N.N.; Mian, Z.; Khatib, A. Influence of origins and bee species on physicochemical, antioxidant properties and botanical discrimination of stingless bee honey. Int. J. Food Prop. 2019, 22, 239-264. [CrossRef]

48. Collymore, C.; Rasmussen, S.; Tolwani, R.J. Gavaging adult zebrafish. J. Vis. Exp. 2013, 78, e50691. [CrossRef] 
49. Kovács, R.; Bakos, K.; Urbányi, B.; Kövesi, J.; Gazsi, G.; Csepeli, A.; Appl, Á.J.; Bencsik, D.; Csenki, Z.; Horváth, Á. Acute and sub-chronic toxicity of four cytostatic drugs in zebrafish. Environ. Sci. Pollut. Res. 2016, 23, 14718-14729. [CrossRef]

50. OECD. OECD Guideline for the Testing of Chemicals; OECD: Paris, France, 2001.

51. Khedkar, P.M.; Jagdale, D.M.; Dhande, S.R. Acute toxicity testing of synthesized pyrazoline derivatives in adult zebrafish. Int. J. Pharm. Sci. Res. 2018, 9, 277-281.

52. Olsen, A.S.; Sarras, M.P., Jr.; Intine, R.V. Limb regeneration is impaired in an adult zebrafish model of diabetes mellitus. Wound Repair Regen. 2010, 18, 532-542. [CrossRef]

53. Eames, S.C.; Philipson, L.H.; Prince, V.E.; Kinkel, M.D. Blood sugar measurement in zebrafish reveals dynamics of glucose homeostasis. Zebrafish 2010, 7, 205-213. [CrossRef] [PubMed]

54. Stanstrup, J.; Broeckling, C.D.; Helmus, R.; Hoffmann, N.; Mathé, E.; Naake, T.; Nicolotti, L.; Peters, K.; Rainer, J.; Salek, R.M. The metaRbolomics toolbox in bioconductor and beyond. Metabolites 2019, 9, 200. [CrossRef] [PubMed]

55. Razali, M.T.A.; Zainal, Z.A.; Maulidiani, M.; Shaari, K.; Zamri, Z.; Mohd Idrus, M.Z.; Khatib, A.; Abas, F.; Ling, Y.S.; Rui, L.L. Classification of raw stingless bee honeys by bee species origins using the NMR-and LC-MS-based metabolomics approach. Molecules 2018, 23, 2160. [CrossRef] [PubMed] 